\title{
Evaluation of the Antimalarial Activity of Ethanol Extracts of the Leaves of Three Plant Species Collected from Yayu Coffee Forest Biosphere Reserve, Southwest Ethiopia
}

\author{
Solomon Yeshanew $\mathbb{D}^{1}$ \\ Worke Gete' \\ Desalegn Chilo ${ }^{2}$ \\ 'Department of Biology, Debre Markos \\ University, Debre Markos, Ethiopia; \\ ${ }^{2}$ Department of Clinical Pharmacy, Mettu \\ University, Mettu, Ethiopia
}

\begin{abstract}
Objective: In the attempt of searching for potential plant derived antimalarial medicines, the aim of the present study was to examine In vivo antimalarial efficacy of crude ethanol extracts of the leaves of Croton macrostachyus, Ruta chalepensis and Vernonia amygdalina using chloroquine (CQ) sensitive strains of Plasmodium berghei in Swiss albino mice.

Methods: To ascertain the safety level of the plant materials, crude extracts underwent oral acute toxicity assessments whereby mice received up to a single dose of $3000 \mathrm{mg} / \mathrm{kg}$. Peter's four day standard antimalarial suppressive test was carried out to determine growth inhibition of parasitemia at tested doses of 400,600 , and $800 \mathrm{mg} / \mathrm{kg}$ of the extracts. Survival time of experimental mice and preliminary phytochemical screenings of the extracts were also done according to the standard procedures.

Results: Extracts of the plant materials did not produce severe acute toxic effects in mice that received up to $3000 \mathrm{mg} / \mathrm{kg}$ in a single dose. Although complete clearance was not recorded, extracts of the plant materials produced dose dependent suppression of the parasitemia. The highest growth inhibition recorded was by extract of $V$. amygdalina $(61.44 \%)$ followed by C. macrostachyus $(59.3 \%)$ at $800 \mathrm{mg} / \mathrm{kg}$ of tested doses. Whereas, complete parasitemia clearance was attributed in mice treated with $25 \mathrm{mg} / \mathrm{kg}$ of CQ. In addition, survival time of experimental mice was recorded and the result showed mice treated with the extracts lived longer than the corresponding negative controls. The phytochemical screening of the extracts revealed the presence of antimalarial active constituents such as alkaloids, saponins, cardiac glycosides, flavonoids, terpenoids, steroids, phenols, and tannins.

Conclusion: The present study, therefore, suggests that crude ethanol extracts of C. macrostachyus, $R$. chalepensis, and $V$. amygdalina are safe and rich with active secondary metabolites which have promising antimalarial effects.
\end{abstract}

Keywords: Antimalarial activity, In vivo, Yayu Biosphere Reserve

\section{Introduction}

Malaria diseases remain one of the most significant causes of morbidity and mortality in resource poor countries, especially in sub-Saharan Africa. Children below the age of five years and pregnant women living in these areas are vulnerable. ${ }^{1,2}$ According to WHO malaria report in 2019, malaria was endemic in 90 countries of the tropical and semitropical areas and it was a cause of death of nearly half a million yearly. ${ }^{3}$
Correspondence: Solomon Yeshanew Email solarm12@yahoo.com 
In Ethiopia, malariais among the leading public health problems and it is the main causes of morbidity and mortality. Plasmodium falciparum and P. vivax are the two main species accounting for $60 \%$ and $40 \%$ of malaria cases, respectively. ${ }^{4}$ Approximately $75 \%$ of the country is malarious and about $68 \%$ of its population live in areas at risk of malaria. ${ }^{5}$

Drug-resistant Plasmodium sp. nowadays is a major problem in malaria control campaign. ${ }^{6}$ Resistance of Plasmodium parasites to the currently available antimalarial medicines has been reported from different parts of the planet. It has been documented for $P$. falciparum, $P$. vivax and P. malariae. However, P. falciparum resistance has been reported in all available antimalarial drugs (amodiaquine, chloroquine, mefloquine, quinine, sulfadoxinepyrimethamine, and artemisinin derivatives). ${ }^{7-9}$

Therefore, it is necessary to develop immediate antimalarial treatments hopefully with the understanding of the mode of actions. One of the best sources for developing new and effective antimalarial drugs that can be easily affordable by the poor living in the malarious endemic tropical countries is traditional medicinal plants and other natural products. ${ }^{10}$

Many plant species continue to be used in traditional medicine for the treatment of malaria and many people depend upon such remedies because of unaffordability and inaccessibility to standard antimalarial drugs. ${ }^{11}$ Since the history of malaria, plants used to play critical roles in treatments of the disease and related pathologies. Peruvian bark (Cinchona spp.) being the first effective sources of plant-based antimalarial drug and the source of the artemisinin (Artemisia annua) demonstrates that plant species are important sources for the discovery of new antimalarial agents. ${ }^{12}$ WHO estimated $80 \%$ of people worldwide rely on herbal medicines for some part of their primary health care; especially in developing countries where malaria is endemic; they strongly depend on traditional medicine as a source for inexpensive treatment of this disease. However, scientific data to validate the antimalarial properties of these herbal remedies are scarce. ${ }^{13,14}$

Since malaria is the number one public health problem in Ethiopia and the majority of people are living in malaria risk rural areas coupled with the inaccessible and unaffordable antimalarial drugs; they strongly depend on traditional medicines particularly herbal remedies to treat the disease and disease related pathologies. ${ }^{15,16}$ There are huge number of plant species used by the people to treat malaria in different parts of the country. Consequently, it is important that traditional medicinal plants should be investigated in order to establish their safety and efficacy as well to determine their potential as source of new plantbased antimalarial drugs. ${ }^{17,18}$ This study thus aimed to examine the potential antimalarial activity of ethanol crude extracts of the leaves of three plant species namely Croton macrostachyus, Ruta chalepensis and Vernonia amygdalina which are collected from Yayu Coffee Forest Biosphere Reserve In vivo using CQ-sensitive strain of Plasmodium berghei in Swiss albino mice.

\section{Materials and Methods Plant Collection and Authentication}

The fresh leaves of the plant material were collected from Yayu Coffee Forest Biosphere Reserve, which is located in Ilu Aba Boor zone, $550 \mathrm{~km}$ southwest from the capital Addis Ababa, Ethiopia during the month of January 2018. Identification and authentication of the collected plant specimen (C. macrostachyus, $R$. chalepensis and $V$. amygdalina) were done at the Ethiopian National Herbarium, Addis Ababa University, Ethiopia. The specimens were then deposited in the herbarium with the collection number of (Meu 01, 02, and 03/2018), respectively.

\section{Preparation of the Crude Extracts}

The collected fresh leaves of the plant was cleaned, cut into pieces and dried under shade. The dried leaves were then ground into coarse powder using an electrical cross bitter mill (IEC, 158VDE0660, Germany). Then, preparation of the crude extracts was carried out by cold maceration technique; soaking the plant powder in 1:12 w/v ratios with ethanol using Erlenmeyer flasks. The flasks containing the plant powder dissolved in ethanol were placed on an orbital shaker (ThermoFisher, USA) at 120 rotations per minute (rpm) for $72 \mathrm{~h}$. The mixtures were filtered using gauze and then the filtrates were passed through Whatman paper number 1 (Wagtech international Ltd, England). The filtrate of the extract was removed under reduced pressure using rotary evaporator (Buchi type TRE121, Switzerland) at $60 \mathrm{rpm}$ and $30^{\circ} \mathrm{C}$ to obtain the crude extract. Then, all the extracts were stored separately in screw capped glass bottles at $-4^{\circ} \mathrm{C}$ until used.

\section{Experimental Animals}

Swiss albino mice 6 to 8 weeks old and weighing 25 to 32 g were obtained from Addis Ababa University and Ethiopian Public Health Institute, Ethiopia. Female mice 
were used for In vivo acute toxicity test and males were used for antimalarial assay. These experimental animals were used according to the NIH Guide for the care and use of laboratory animals. ${ }^{19}$

\section{Experimental Pathogen and Infection Procedure}

The antimalarial evaluations of the extracts were performed using CQ-sensitive strain of Plasmodium berghei of the rodent malaria parasite. It was collected from Ethiopian Public Health Institute and kept alive by continuous intraperitoneal passage in mice on weekly basis. Percent parasitemia of the donor mouse was first determined; about 20 to $30 \%$ parasitemia and blood was collected through gentle cardiac puncher from the donor mouse using syringe after it has been sacrificed by chloroform. Then, $1 \mathrm{~mL}$ of blood was diluted with $4 \mathrm{~mL}$ of physiological saline $(0.9 \%)$ and $1 \mathrm{~mL}$ of the dilution expected to contain $5 \times 10^{6}$ of infected erythrocytes. Therefore, each mouse was infected on day zero $\left(D_{0}\right)$ intraperitoneally with $0.2 \mathrm{~mL}$ dilution of infected blood (standard inoculum) containing approximately $1 \times 10^{6} \mathrm{P}$. berghei parasitized red blood cells. ${ }^{20,21}$

\section{Oral Acute Toxicity Assessments}

Twenty-five healthy female mice were used to test the acute toxicity of each crude extract through oral administration. The mice were randomized into five groups of five mice per group. They were then subjected to fast overnight and the four groups were provided with 500, 1000, 2000, and $3000 \mathrm{mg} / \mathrm{kg}$ of the extract dissolving with $0.4 \mathrm{~mL}$ of $20 \%$ of dimethyl sulfoxide (DMSO) for each mouse respectively. The fifth group (the control) was given the same volume of the vehicle for each mouse in the group. Then, the presence and absence of acute toxic signs such as hair erection, lacrimation, reduced motor and feeding activities, urination, convulsion, and mortality within $24 \mathrm{~h}$ were recorded.

\section{In vivo Antimalarial Suppressive Tests}

In order to determine the antimalarial suppressive effect of the plant extracts, Peters' 4-day suppressive test was subjected using $P$. berghei infection in mice. ${ }^{20}$ For each extract, 20 mice randomly grouped in to four categories of equal number of mice in each group were used. At the first day $\left(\mathrm{D}_{0}\right)$ of the experiment, each mouse intended for the experiment was infected by $P$. berghei parasitemia using standard inoculums $\left(1 \times 10^{6} P\right.$. berghei infected $\mathrm{RBCs})$ through intraperitoneal parasite inoculation. ${ }^{21}$
After three hours of parasite inoculation, the three groups were administered with 400,600 , and $800 \mathrm{mg} / \mathrm{kg}$ of extract by dissolving the extract with $0.2 \mathrm{~mL}$ of the respective vehicle for each mouse orally using a standard oral needle for four consecutive days in a 24-h schedule. The other two groups were used as a negative control and positive control which were given $0.2 \mathrm{~mL}$ of the same vehicle and $25 \mathrm{mg} / \mathrm{kg}$ of CQ respectively. ${ }^{20,22}$

\section{Parasitological Study}

On the fifth day $\left(\mathrm{D}_{4}\right)$ of the experiment, a drop of fresh blood specimen was taken from the tail snip of each mouse and thin smears using Giemsa stain were prepared for microscopy examination. ${ }^{21}$ Parasitemia were then examined under light microscopy starting from power of 10 and then up to power $100 .{ }^{22}$ Ten fields of visions were taken from different angles of each slide and percentage of $P$. berghei infected RBSc were calculated from the total RBSc encompassed in the fields of vision. Finally, percentage parasitemia and parasite suppression were calculated using the following two formulas as Fidock et al have described. ${ }^{23}$

$$
\begin{gathered}
\text { \%Parasitemia }=\frac{\text { Numbere of Infected RBCs x } 100}{\text { Total number of RBCs }} \\
\text { \%Suppression }=100-\left(\begin{array}{l}
\text { Mean parasitemia in } \\
\text { the study group x100 } \\
\begin{array}{l}
\text { Mean parasitemia in } \\
\text { negative control group }
\end{array}
\end{array}\right)
\end{gathered}
$$

\section{Determination of Mean Survival Time of Mice}

Mortality rates were supervised daily and the number of days from the time of parasite inoculation to death were recorded for each mouse in treatment and control groups throughout the follow-up observation period. Then, the mean survival time (MST) for each group was calculated using a mathematical formula as described by Mengiste et al. ${ }^{24}$

$$
\mathrm{MST}=\frac{\text { Sum of survival time of all mice in agroup }}{\text { Total number of mice in that group }}
$$

\section{Phytochemical Screening}

The qualitative preliminary phytochemical screening of the ethanol extracts of the leaves of $C$. macrostachyus, $R$. chalepensis and $V$. amygdalina were made for the identification of selected antimalarial active secondary metabolites such as alkaloids, saponins, glycosides, flavonoids, 
terpenoids, steroids, phenols, and tannins according to the standard procedures and operation manual. ${ }^{25,26}$

\section{Statistical Analysis}

SPSS version 20 statistical software was used for analysis of the data. One sample $t$-test was employed to calculate the mean value of parasitemia and survival time for all variables. ANOVA was also considered to compare the level of parasitemia and survival time of $P$. berghei infected mice between the control and extract treated groups at $\mathrm{D}_{4}$ of the study, respectively. All results were presented by the mean \pm SEM (standard error of the mean) and statistical significance was considered when $P<0.05$ at the $95 \%$ of confidence interval.

\section{Results}

\section{Extract Yields}

Percentage yield of crude ethanol extracts of the leaves of C. macrostachyus, $R$. chalepensis and $V$. amygdalina is presented in Table 1. A 1:12 w/v ratio of cold maceration technique of extraction was employed and yields comprised of 14 to $22 \%$ of the total plant material used.

\section{Acute Toxicity}

According to the data from Table 2, crude ethanol extracts of the leaves of $C$. macrostachyus, R. chalepensis and $V$. amygdalina did not cause death of mice within 24 $\mathrm{h}$ after being administered with 500, 1000, 2000, and $3000 \mathrm{mg} / \mathrm{kg}$ of the extracts. Minor gross behavioral and physical changes such as decreased feeding activities, depression, and hair erection were seen for about half a day at 2000 and $3000 \mathrm{mg} / \mathrm{kg}$ dose of the extracts received by the mice. However, they returned back to normal physical and motility conditions. They were also active during five days of inspection period.

\section{Antimalarial Suppressive Tests}

Extract treated $P$. berghei infected mice produced dose dependent and varying degree of antimalarial suppressive effects. However, complete clearance of parasitemia was not recorded. The positive control group which was treated with $25 \mathrm{mg} / \mathrm{kg}$ of $\mathrm{CQ}$ cleared the parasitemia at $\mathrm{D}_{4}$ of postinfection (Table 3).

Compared to the negative control, extract treated $P$. berghei infected mice showed significant suppressive effects. It was detected that the level of $P$. berghei parasitemia in the negative control group was $46.53 \pm 1.23$ while the level of parasitemia in mice administered with extracts of $V$. amygdalina at the highest dose was 17.94 \pm 0.31 at the fifth day postinfection. Similarly, the respective crude extracts of $R$. chalepensis and C. macrostachyus at a dose of $800 \mathrm{mg} / \mathrm{kg}$ produced $56.72 \%$ and $59.30 \%$ parasitemia suppressive effects, respectively when comparedwith the negative control group. However, among

Table I Percentage Yield of Ethanol Crude Extracts of the Leaves of C. macrostachyus, R. chalepensis, and V. amygdalina

\begin{tabular}{|l|c|c|c|c|c|}
\hline Plant Species & Dry Powder (g) & Solvent Volume (mL) & Ratio (w/v) & Yield (g) & Yield (\%) \\
\hline R. chalepensis & 80 & 1000 & $1: 12$ & 17.76 & 22.2 \\
C. macrostachyus & 80 & 1000 & $1: 12$ & 11.20 & 14 \\
V. amygdalina & 80 & 1000 & $1: 12$ & 12.08 & 15.1 \\
\hline
\end{tabular}

Table 2 Acute Toxic Manifestation Seen After Administration of Ethanol Extracts of $C$. macrostachyus, R. chalepensis and V. amygdalina in Female Mice

\begin{tabular}{|c|c|c|c|c|c|c|c|c|c|c|c|c|}
\hline \multirow[t]{3}{*}{ Response } & \multicolumn{12}{|c|}{ Extract Treatment (mg/kg) } \\
\hline & \multicolumn{4}{|c|}{ C. macrostachyus } & \multicolumn{4}{|c|}{ R. chalepensis } & \multicolumn{4}{|c|}{ V. amygdalina } \\
\hline & 500 & 1000 & 2000 & 3000 & 500 & 1000 & 2000 & 3000 & 500 & 1000 & 2000 & 3000 \\
\hline Hair erection & A & $A$ & $P$ & $P$ & A & A & $P$ & $P$ & A & A & A & $P$ \\
\hline Lacrimation & A & A & A & A & A & $A$ & A & $P$ & A & A & $P$ & $P$ \\
\hline Decreased activity & $A$ & $A$ & $A$ & $A$ & $A$ & $A$ & $A$ & $P$ & A & A & $A$ & $P$ \\
\hline Decreased appetite & $A$ & $P$ & $P$ & $P$ & A & A & $P$ & $P$ & $A$ & $P$ & $P$ & $P$ \\
\hline Depression & $A$ & $P$ & $P$ & $P$ & A & $P$ & $P$ & $P$ & $P$ & $P$ & $P$ & $P$ \\
\hline Mortality & $A$ & A & A & A & A & $A$ & $A$ & $A$ & $A$ & A & A & $A$ \\
\hline
\end{tabular}

Abbreviations: A, absent; P, present. 
Table 3 In vivo Antimalarial Suppressive Effect of Ethanol Crude Extracts of C. macrostachyus, R. chalepensis and V. amygdalina in Mice

\begin{tabular}{|l|c|c|c|c|}
\hline Treatments & Dose $\mathbf{( m g / k g )}$ & \% Parasitemia & \% Suppression & P-value \\
\hline DMSO (5\%) & $0.2 \mathrm{~mL}$ & $46.53 \pm 1.23$ & 0.00 & - \\
\hline V. amygdalina & 400 & $25.47 \pm 0.61$ & 45.26 & 53.06 \\
& 600 & $21.84 \pm 0.74$ & 61.44 & 0.74 \\
& 800 & $17.94 \pm 0.31$ & 45.90 & 0.18 \\
\hline R. chalepensis & 400 & $25.17 \pm 0.94$ & 50.01 & 0.78 \\
& 600 & $23.26 \pm 0.59$ & 56.72 & 0.85 \\
\hline C. macrostachyus & 800 & $24.14 \pm 0.28$ & 47.32 & 0.63 \\
& 400 & $20.43 \pm 0.25$ & 56.10 & 0.32 \\
\hline CQ & 600 & $18.94 \pm 0.32$ & 59.30 & 0.04 \\
\hline
\end{tabular}

Abbreviations: CQ, chloroquine; ND, not done; DMSO, dimethyl sulfoxide.

the three plant crude extracts, the highest parasitemia suppression was recorded in the $V$. amygdalina extract treated group followed by C. macrostachyus.

\section{Survival Time Determination}

Treatment with extracts of the plant materials improved the life expectancy of $P$. berghei infected mice while the corresponding negative control were treated with $0.2 \mathrm{~mL}$ of $5 \%$ DMSO died sooner (Table 4). Dose of the extracts were found associated significantly with the survival time of mice in the treatment groups.

In mice, the higher parasitemia suppression recorded, the longer they lived. Thus, parasitemia-infected mice treated with $800 \mathrm{mg} / \mathrm{kg}$ of plant material crude extracts for the three species of study plant produced the highest percent suppression of parasitemia and lived the longest time when compared with lower dose treatments and the negative control groups.

\section{Preliminary Phytochemical Screenings}

As shown from (Table 5), the presence and absence of antimalarial active secondary metabolites among extracts of the three plant materials are demonstrated. Alkaloids, tannins and terpenoids were found from all the three extracts whereas steroids from $V$. amygdalina, and flavonoids and saponins from $R$. chalepensis were not detected.

\section{Discussion}

Although medicinal plants are assumed to be safe, potentially toxic species were discovered and therefore,

Table 4 Survival Time of Crude Ethanol Extracts of C. macrostachyus, R. chalepensis and V. amygdalina Treated P. berghei Infected Mice

\begin{tabular}{|c|c|c|c|c|}
\hline Treatments & Dose (mg/kg) & \% Suppression & Survival Time/day & $P$-value \\
\hline DMSO (5\%) & $0.2 \mathrm{~mL}$ & 0.00 & $6.20 \pm 0.85$ & - \\
\hline \multirow[t]{3}{*}{ V. amygdalina } & 400 & 45.26 & $9.20 \pm 0.58$ & 0.66 \\
\hline & 600 & 53.06 & $11.4 \pm 1.12$ & 0.32 \\
\hline & 800 & 61.44 & $14.60 \pm 0.68$ & 0.19 \\
\hline \multirow[t]{3}{*}{ R. chalepensis } & 400 & 45.90 & $7.00 \pm 0.32$ & 0.39 \\
\hline & 600 & 50.01 & $9.00 \pm 0.84$ & 0.02 \\
\hline & 800 & 56.72 & $10.60 \pm 0.68$ & 0.19 \\
\hline \multirow[t]{3}{*}{ C. macrostachyus } & 400 & 47.32 & $9.80 \pm 0.58$ & 0.66 \\
\hline & 600 & 56.10 & $10.60 \pm 0.68$ & 0.19 \\
\hline & 800 & 59.30 & $12.40 \pm 0.68$ & 0.19 \\
\hline $\mathrm{CQ}$ & 25 & 100.00 & ND & ND \\
\hline
\end{tabular}


Table 5 Secondary Metabolites Identified from the Ethanol Crude Extracts of C. macrostachyus, R. chalepensis and V. amygdalina

\begin{tabular}{|l|c|c|c|}
\hline \multirow{2}{*}{ Phytochemicals } & \multicolumn{3}{|c|}{ Results } \\
\cline { 2 - 4 } & C. macrostachyus & R. chalepensis & V. amygdalina \\
\hline Alkaloids & + & + & + \\
Flavonoids & + & - & + \\
Cardiac glycosides & + & + & - \\
Phenols & - & + & + \\
Saponins & + & - & + \\
Steroids & + & + & + \\
Tannins & + & + & + \\
Terpenoids & + & + & + \\
\hline
\end{tabular}

determination of the safety level of plant extracts needs to be considered before being used for treatment purposes. ${ }^{27,28}$ Thus, acute toxicity tests of the crude ethanol extracts of C. macrostachyus, $R$. chalepensis and $V$. amygdalina were carried out among healthy mice up to $3000 \mathrm{mg} / \mathrm{kg}$ of the extracts orally. Slight physical and behavioral changes such as depression and hair erection were found for about half a day. However, absence of severe acute toxic symptoms such as impaired movement, listlessness, reduced motor activity, and mortality within $24 \mathrm{~h}$ and survival of mice during the follow-up period justifies that the extracts are safe and do not produce oral toxicity at the tested dosages. It is also an indication that the estimated oral median lethal dose $\left(\mathrm{LD}_{50}\right)$ is not toxic and the extracts at $6000 \mathrm{mg} / \mathrm{kg}$ body weight could be nonlethal. ${ }^{28}$ This is also one justification why these plant species are widely used in traditional treatment of malaria in Ethiopian folk medicines. $^{29}$

In the present study, all the three crude extracts established statistically significant $(P<0.05)$ and dose dependent $P$. berghei parasitemia suppression when compared with the respective negative control. These antimalarial activity of crude ethanol extracts of the plant materials supposed to be by the presence of antimalarial active phytochemical constituents such as alkaloids, saponins, cardiac glycosides, flavonoids, terpenoids, steroids, phenols, and tannins, which are attributed in the antiplasmodial activities alone or the synergetic effects. ${ }^{30-33}$ Many other antimalarial active plant species including the source of artemisinin (Artemisia annua) also possess the abovementioned secondary metabolites. $^{34,35}$

Krettli et al in their review demonstrated that a plantbased compound is considered an active antimalarial when it produces $30 \%$ or more inhibition against parasitemia of P. berghei in mice. The above generalization supports the result of the present study in which all plant extracts produced significant parasite suppression by more than $45 \%$ although complete clearance of the parasite is not yet detected. ${ }^{21}$ Similar studies on other plant species such as Acacia nilotica, Morinda lucida, Otostegia integrifolia, Clerodendrum myricoides, Dodonea angustifolia and Aloe debrana and Asparagus africanus also reported that extracts of the plant species produced dose dependent and significant parasitemia growth inhibition against P. berghei in mice. ${ }^{36-40}$ The present study, therefore, could be evidence demonstrating the relevance of these herbal medicines that are promising in the search for new antimalarial medicines.

Several plant-based medicinal derivatives have identified antiplasmodial mode of actions to exert antimalarial activity by interfering with the parasite's ability to eliminate the toxic byproduct of hemoglobin digestion or directly killing young intraerythrocytic malaria parasites or inhibiting protein synthesis of the parasite or by other unknown modes of action or using synergetic mechanisms of actions of two or more. ${ }^{41-43}$ However, plant extracts of the present study are crude; the antimalarial action could be the result of synergetic effects of different phytochemical constituents. However, the mechanisms of action have not yet been explained in the study.

Mice treated with the plant extracts lived longer compared to the negative controls. This justifies the crude ethanol extracts of the plant materials suppressed P. berghei parasitemia and probably reduced the overall pathogenic effect of the parasite in the experimental mice. A justification, therefore, can be provided that the plant material could probably be used to inhibit further multiplication of $P$. parasitemia until the infected individuals get modern medical treatments. ${ }^{44}$

Even though extract-treated mice lived longer than the ones fed with the vehicle, the highest survival times were recorded at a dose of $800 \mathrm{mg} / \mathrm{kg}$ body weight of the extracts. However, the life span of mice treated with the extracts was not significantly higher than the negative control. This is probably because the plant extracts did not clear all parasitemia from the mice. Furthermore, ethanol used for dissolving plants material confirming the traditional usage of these plant species as a malaria remedy and the use of water and ethanol (local alcohols) as common solvents in traditional medicine. 


\section{Conclusion}

Crude ethanol extracts of the leaves of C. macrostachyus, $R$. chalepensis and $V$. amygdalina produced significant dose dependent antimalarial activity In vivo against P. berghei in Swiss albino mice. The extracts are found safe in mice that received up to $3000 \mathrm{mg} / \mathrm{kg}$ in a single dose. The phytochemical screenings of the extracts also revealed the presence of potent antimalarial secondary metabolites. Thus, these plant species could potentially be used as alternative sources for the development of a new plant-based antimalarial agent.

\section{Limitation of the Study}

This was a preliminary study which aimed to assess only the antiplasmodium potential of the crude extracts of the plant materials. The mode of action of the extracts against the parasite and the host cell was not considered in the present study. However, a recommendation of further bioactivity guided fractionation of the extracts could permit the isolation of active compound and ablity to understand its mechanism of action.

\section{Data Sharing Statement}

Additional questions or information may be obtained by contact the corresponding author, Solomon Yeshanew.

\section{Ethical Approvals}

The study was carried out after having ethical clearance endorsement from Research Ethical and Technical Review Clearance Committee (RETRCC), College of Medical Sciences, Mettu University, Ethiopia. The committee approved all experimental protocols are in compliance with the NIH and ARRIVE Guidelines for the care and use of laboratory animals.

\section{Acknowledgments}

Mettu University owes the gratitude for the materials and reagents support to carry out this study. Phytochemical screenings of the extracts were kindly done at Addis Ababa University and should be acknowledged.

\section{Author Contributions}

All authors conceived the study, carried out the field and laboratory works, involved for analysis and interpretation of the data and took part in drafting the manuscript. They critically read, revised for intellectually important contents, gave the final approval of the version to be published and agreed to be accountable for all aspects of the work.

\section{Funding}

The present study supported financially by the Research and Technology Transfer Office of Mettu University through annual staff research fund opportunity (grant number: MeU-RTTD-2009-1-28).

\section{Disclosure}

The authors report no conflicts of interest in this work.

\section{References}

1. Gaston RT, Ramroop S. Prevalence of and factors associated with malaria in children under five years of age in Malawi, using malaria indicator survey data. Heliyon. 2020;6(5):e03946. doi:10.1016/j.heliyon.2020.e03946

2. WHO. World malaria report: world Health Organization. Geneva; 2016. Available from: https://www.who.int/malaria/publications/ world-malaria-report-2016/report/en/. Accessed February 17, 2019.

3. WHO. World malaria report: world Health Organization. Geneva; 2019. Available from: https://www.who.int/publications/i/item/ 9789241565721. Accessed April 20, 2021.

4. FMOH. Ethiopia national malaria indicator survey 2015. Addis Ababa, Ethiopia: Ethiopian Public Health Institute; 2016. Available from: https://www.ephi.gov.et/images/pictures/download2009/MIS2015-Final-Report-December- 2016.pdf. Accessed June 14, 2019.

5. Girum T, Shumbej T, Shewangizaw M. Burden of malaria in Ethiopia, 2000-2016: findings from the global health estimates 2016. Trop Dis Travel Med Vaccines. 2019;5:11. doi:10.1186/ s40794-019-0090-z

6. WHO. Tackling antimalarial drug resistance: Launch of the WHO report on antimalarial drug efficacy, resistance and response: 10 years of surveillance (2010-2019). World Health Organization. 2020; WHO/UCN/GMP/2020.07. Available from: https://www.who.int/ news-room/events/detail/2020/11/19/default-calendar/report-onantimalarial-drug-efficacy-resistance-and-response-10-years-ofsurveillance-(2010-2019). Accessed September 21, 2020.

7. WHO. Guidelines for the treatments of malaria. Third edition. Geneva, Switzerland; 2015. Available from: https://www.who.int/pub lications/i/item/9789241549127. Accessed November 23, 2020.

8. Noedl H, Se Y, Schaecher K, Smith BL, Socheat D, Fukuda MM. Evidence of artemisinin-resistant malaria in Western Cambodia. N Engl J Med. 2008;359:2619-2620. doi:10.1056/NEJMc0805011

9. Dondorp AM, Nosten F, Yi P, et al. Artemisinin resistance in Plasmodium falciparum. Malaria $N$ Engl $J$ Med. 2009;361:455-467. doi:10.1056/NEJMoa0808859

10. Ginsburg H, Deharo E. A call for using natural compounds in the development of new antimalarial treatments: an introduction. Malar J. 2011;10:1-7. doi:10.1186/1475-2875-10-S1-S1

11. Wright CW. Plant derived antimalarial agents: new leads and challenges. Phytochem Rev. 2005;4:55-61. doi:10.1007/s11101-0053261-7

12. Yarnell E, Abascal K. Botanical prevention and treatment of malaria. Alt Comp Ther. 2004;1:206-210. doi:10.1089/1076280041580332

13. WHO. Traditional herbal remedies for primary health care. New Delhi, India: Regional office for South East Asia, Indraprastha Estate, Mahatma Gandhi Marg; 2010. Available from: https://apps. who.int/iris/handle/10665/206024. Accessed March 12, 2020. 
14. Jurga A, Tomása T, Pividalb J. Antimalarial activity of some plant remedies in use in Marracuene, southern Mozambique. J Ethnopharmacol. 1991;32(1-2):79-83. doi:10.1016/0378-8741(91)90165-A

15. Bekele E Study on actual situation of medicinal plants in Ethiopia. Prepared for JAICAF (Japan Association for International Collaboration of Agriculture and Forestry); 2007. Available from: http://www.endashaw.com. Accessed January 15, 2018.

16. Kassaye KD, Amberbir A, Getachew B, Mussema YA. Historical overview of traditional medicine practices and policy in Ethiopia. Eth J Health Dev. 2006;20(2):127-134.

17. Bandaranayake MW. Quality control, screening, toxicity, and regulation of herbal drugs. In: Ahmad I, Aqil F, Owais M, editors. Modern Phytomedicine. Turning Medicinal Plants into Drugs. KGaA, Weinheim: WILEY-VCH Verlag GmbH \& Co; 2006:25-57. doi:10.1002/9783527609987.ch2

18. Soetan KO, Aiyelaagbe OO. The need for bioactivity safety evaluation and conservation of medicinal plants. J Med Plants Res. 2009;3:324-328.

19. NRC (National Research Council). Guide for the care and use of laboratory animals. Institute of laboratory animal resources commission on life sciences. Washington, D.C: National Academy Press; 1996. Available from: https://grants.nih.gov/grants/olaw/guide-forthe-care-and-use-of-laboratory-animals.pdf. Accessed July 19, 2018.

20. Peters W. Rational methods in the search for antimalarial drugs. Trans R Soc Trop Med Hyg. 1967;61:400-410. doi:10.1016/00359203(67)90015-6

21. Krettli AU, Adebayo JO, Krettli LG. Testing of natural products and synthetic molecules aiming at new antimalarials. Curr Drug Targets. 2009;10:261-270. doi:10.2174/138945009787581203

22. WHO. Basic laboratory methods in medical parasitology. Parasitology laboratory manual. Geneva, Switzerland: World health Organization; 1991. Available from: https:/www.who.int/malaria/pub lications/atoz/9241544104_part1/en/. Accessed April 23, 2019.

23. Fidock DA, Rosenthal PJ, Croft SL, Brun R, Nwaka S. Antimalarial drug discovery efficacy models for compound screening. Drug Discov. 2004;3(6):509-520. doi:10.1038/nrd1416

24. Mengiste B, Makonnen E, Urga K. In vivo antimalarial activity of Dodonaea Angustifolia seed extracts against Plasmodium berghei in mice model. Momona Eth J Sci. 2012;4(1):47-63. doi:10.4314/mejs.v4i1.74056

25. Yadav RNS, Agarwala M. Phytochemical analysis of some medicinal plants. J Phytol. 2011;3:10-14.

26. Beroa J, Fre'de'richb M, Quetin-Leclercqa J. Antimalarial compounds isolated from plants used in traditional medicine. J Pharm Pharmacol. 2009;61(11):1401-1433. doi:10.1211/jpp/61.11.0001

27. Ajaiyeoba E, Falade M, Ogbole O, Okpako L, Akinboye D. In vivo antimalarial and cytotoxic properties of Annona senegalensis extract. Afr J Tradit Complement Altern Med. 2006;3:137-141. doi:10.4314/ ajtcam.v3i1.31148

28. Verma S, Singh SP. Current and future status of herbal medicines. Vet World. 2008;2(2):347-350. doi:10.5455/vetworld.2008.347-350

29. CDER. Single dose acute toxicity testing for pharmaceuticals. U.S. Food and Drug Administration; 1996. Available from: https://www. fda.gov/regulatory-information/search-fda-guidance-documents/sin gle-dose-acute-toxicity-testing-pharmaceuticals. Accessed October $27,2020$.

Journal of Experimental Pharmacology

\section{Publish your work in this journal}

The Journal of Experimental Pharmacology is an international, peerreviewed, open access journal publishing original research, reports, reviews and commentaries on all areas of laboratory and experimental pharmacology. The manuscript management system is completely

Submit your manuscript here: https://www.dovepress.com/journal-of-experimental-pharmacology-journal
30. Giday M, Teklehaymanot T, Animut A, Mekonnen Y. Medicinal plants of the Shinasha, Agew-awi and Amhara peoples in northwest Ethiopia. J Ethnopharmacol. 2007;110(3):516-525. doi:10.1016/j. jep.2006.10.011

31. Offor CE. Comparative Chemical Analyses of Vernonia amygdalina and Azadirachta indica Leaves. IOSR J Pharm Biol Sci. 2014;9 (5):73-77. doi:10.9790/3008-09527377

32. Abeje A, Fikre M, Belayhun K. Isolation and characterization of terpene from leaves of Croton macrostachyus (Bissana). J Med Plants Res. 2016;10(19):256-260. doi:10.5897/JMPR2016.6082

33. Kacem M, Kacem I, Simon G, Ben MA, Chaabouni S, Elfeki AB. Phytochemicals and biological activities of Ruta chalepensis L. growing in Tunisia. Food Biosci. 2015;12:73-83. doi:10.1016/j. fbio.2015.08.001

34. Tesso H Isolation and structure elucidation of natural products from plants. Dissertation. Hamburg: Institute of Organic Chemistry, University of Hamburg ; 2004. Available from: https://ediss.sub.unihamburg.de/bitstream/ediss/882/1/Dissertation_final_version.PDF. Accessed July 07, 2012.

35. Zhang L, Demain AL. Natural products: drug discovery and therapeutic medicines. Humana press Inc, United States of America; 2005.

36. Alli LA, Adesokan AA, Salawu OA, Akanji MA, Tijani AY. Antiplasmodial activity of aqueous root extract of Acacia nilotica. Afr J Biochem Res. 2011;5:214-219.

37. Unekwuojo GE, James O, Olubunmi AR. Suppressive, curative and prophylactic potentials of Morinda lucida (Benth) against erythrocytic stage of mice infective chloroquine sensitive Plasmodium berghei NK-65. Br J Appl Sci Technol. 2011;1:131-140. doi:10.9734/BJAST/ 2011/273

38. Yeshanew S, Mekonnen Y. Antimalarial activity of Otostegia integrefolia leaf extracts against Chloroquine sensitive strain of Plasmodium berghei in mice. Pharmacologyonline. 2013;2:84-89.

39. Deressa T, Mekonnen Y, Animut A. In vivo antimalarial activities of Clerodendrum myricoides, Dodonea angustifolia and Aloe debrana against Plasmodium berghei. Eth J Health Dev. 2010;24:25-29. doi:10.4314/ejhd.v24i1.62941

40. Dikasso D, Makonnen E, Debella A, et al. Antimalarial activity of Withania somnifera L. Dunal in mice. Eth Med J. 2006;44:279-285. PMID: 17447395.

41. White NJ. Qinghaosu (artemisinin): the price of success. Science. 2008;320(5874):330-334. doi:10.1126/science. 1155165

42. Bassy AS, Okokon JE, Etim EI, Umoh FU, Bessy E. Evaluation of the In vivo antimalarial activity of ethanolic leaf and stem bark extracts of Anthocleista djalonensis. Ind J Pharmacol. 2009;41 (6):258-261. doi:10.4103/0253-7613.59924

43. Hobbs C, Duffy P. Drugs for malaria: something old, something new, something borrowed. F1000 Biol Rep. 2011;3:24. doi:10.3410/B3-24

44. Yeshanew S, Mekonnen Y. The effect of Otostegia integrefolia leaf extracts on the packed cell volume, body weight and survival time of Plasmodium berghei infected mice. Int J Trop Med. 2013;8 (6):129-134. doi:10.36478/ijtmed.2013.129.134

online and includes a very quick and fair peer-review system. Visit http://www.dovepress.com/testimonials.php to read real quotes from published authors. 